\title{
LEVEL OF AWARENESS OF OUTCOME-BASED EDUCATION OF ENGLISH SYLLABUS DESIGNERS AT THAI NGUYEN UNIVERSITY
}

\section{Que Thi Nguyen ${ }^{+}$, Hoa Phuong Pham}

\section{Article History}

Received: July 15, 2019

Accepted: September 22, 2019

Published: September 30, 2019

\section{Keywords}

Outcome-based education, level of awareness, English syllabus designers, Thai Nguyen University

\author{
Thai Nguyen University of Sciences, Vietnam \\ ${ }^{+}$Corresponding author • Email: quenguyentnu@gmail.com
}

\section{INTRODUCTION}

Outcome-based education (OBE) is a paradigm shift for most Vietnamese teachers as it is a departure from the more familiar content-based, test-driven traditional curriculum. In Vietnam, OBE is a newly adopted method and the lack of thorough and clear instructions on this approach has caused immense confusion and mismatches between the requirements of Ministry of Education and Training (MOET) and the implementation of educational experts. According to $\mathrm{Vu}$ (2011), MoET launched Directive No. 7823 requiring higher educational institutions to issue the outcome statements of their training programs with outstanding qualities and differences which are demonstrated by graduates' expected competencies for benchmarking and accountability. However, many workshops and seminars held by educational experts to help actualize the above directive just only focused on guiding teachers how to write learning outcomes of particular subjects. She also stressed that this mismatch happened due to the confusion over the term "learning outcomes" when translated into Vietnamese language. Furthermore, the superficial understanding on OBE has caused many universities and colleges to rewrite their outcome statements which are either too vague or unmeasurable or, in some cases, transparent and detailed yet irrelevant to their teaching and learning activities, thus unattainable. Therefore, it is essential that educators be equipped with a thorough understanding of the OBE approach in the aim of a better implementation of OBE in their specific context.

Thai Nguyen University (TNU), a key education center in the northern region of Vietnam, offers hundreds of training programs for bachelor to doctoral students in almost all fields. At the ten member colleges/universities, the internal English divisions or departments are responsible for and free to select teaching materials and design training curricula. Based on observation, many teachers have a habit of designing their teaching syllabi entirely based on the tables of contents of imported textbooks from English speaking countries. Such practices of designing English program syllabi without considering local factors such as students' levels and learning styles, expected graduates' attributes, employers' needs, the rush coverage of inauthentic textbook contents and students' insufficient selfstudying competencies have impeded graduates to achieve the compulsory expected outcome language proficiency as stated in Document 758/TB-DHTN by TNU Director (TNU Project, 2013). Therefore, in order to restructure an English program in the light of OBE to enhance graduates' competencies and meet society's demands for English proficiency, the first crucial step should be to investigate the level of awareness on OBE of English syllabus developers so that appropriate training could be offered to these educators with the aim to better English program syllabi and curricula. 
With the aforementioned observations, the study on "Level of Awareness on Outcome-Based Education of English Syllabus Designers at Thai Nguyen University" has come into conception with the main aims of investigating their level of awareness on OBE and their perceptions on factors that affect the implementation of OBE at TNU.

\section{LITERATURE REVIEW}

The research is based upon theoretical backgrounds of various educators and linguists such as Hoffman (1996), Marina (2008:18), Biggs and Tang (2007), and Caguimbal et. al. (2013) - advocates of the implementation of Outcome-based Education (OBE) at higher education institutions.

Hoffman (1996) justifies the alarming situation in which a growing number of high-school graduates could not adapt to real world changes. As a result, educational leaders decided to shift the educational focus from covering the amount of in-class learning time to determining learners' outcome competencies. This renovating approach is called Outcome-Based Education.

Spady (1994), a leading expert of OBE, points out that "outcome-based education means organizing teaching activities based on expected outcomes to achieve expected results". To be specific, this means starting with identifying learners' expected outcomes then organizing teaching and learning as well as assessment to warranty the effectiveness of the learning process. He also stated that outcome-based education is designed so that all students are equipped with necessary knowledge, skills and qualities to succeed after graduation.

Outcomes based education (OBE) is a process that involves the restructuring of curriculum, assessment and feedback in education to reflect learning competencies and mastery of high order knowledge rather than the accumulation of course credits. Thus the primary aim of OBE is to facilitate learners' desired internal changes, by enhancing knowledge, developing skills and/or positively influencing attitudes, values and judgment. OBE embodies the idea that the best way to learn is to first determine what needs to be achieved. Once the end goal (product or outcome) has been determined the strategies, processes, techniques, and other approaches and means can be put into place to achieve the goal.

Agreeing on that, Marina (2008:18) emphasizes that OBE is a paradigm shift for most teachers as it is a departure from the content-based, test-driven traditional curriculum they were trained to teach. In contrast to the former curriculum, OBE focuses on what learners know and can do. Therefore, the starting point of any outcome-based curriculum or lesson is not the learning content, but rather the intended results of learning, i.e. the knowledge, skills and values expected from learners. Learning curricula and lesson plans are implemented to facilitate learners to achieve desired results. Meanwhile, valid and reliable assessment approaches are indispensable to help teachers justify whether learners have achieved the expected outcomes.

In course syllabus design, Biggs and Tang (2007) propose the concept of Constructive Alignment in the light of OBE which assumes that learning objectives, assessment methods, and teaching and learning activities are intentionally aligned so that learning outcomes can be achieved. More specifically, the process of designing a course starts with the teachers' planning the intended learning outcomes in terms of knowledge, skills, values and attitudes the students at the end of the learning process. All these expected outcomes then serve as the basis for teachers to select suitable teaching and learning activities and tasks to assess. The report on students' performance through assessment will reveal learners' level of achievement of expected outcomes and also used to plan the next teaching objectives and to review the existing teaching, learning and assessment practices.

In a study of the level of awareness of OBE, Caguimbal et. al. (2013) concluded that all participants are well aware that OBE is really beneficial to students and community. Therefore, in order to successfully shift from traditional to OBE programs, it is urgent that educators, particularly syllabus designers should be equipped with clear understanding of the approach so that they can restructure the programs according to OBE standards.

\section{RESEARCH METHODS AND RESULTS}

\subsection{Research methods}

The research employed the descriptive method to find out educator respondents' level of awareness on OBE and factors affecting the implementation of OBE at TNU. The survey respondents of this study were 12 English lecturers who were in charge of designing the English syllabi at five member institutions of Thai Nguyen University namely TNU of Education, TNU of Sciences, TNU of Information and Technology, TNU of Medicine and Pharmacy, and TNU of Agriculture and Forestry. Descriptive design endeavors to illustrate and interpret the situation of the research. In this study, it was used to describe the respondents' profile, level of awareness of OBE and perceptions of factors that affect the implementation of OBE at TNU. 
The research instrument used in the study is a self-devised questionnaire with three parts including the respondents' demographics, level of awareness on OBE and factors affecting the implementation of OBE in Vietnam using the Likert's scale rating.

The data gathered were described statistically using percentage, frequency for respondents' profiles; mean and standard deviation for educators' level of awareness on OBE and factors affecting OBE implementation.

\subsection{Research results}

Following are findings and interpretation of the data with supported research results and evidences.

\subsubsection{The respondents' demographics}

Results of the questionnaire clearly reveal the profile of the twelve teachers responsible for designing the General English Program (GEP) syllabi at five different higher education institutions of TNU.

Regarding age, 7 of the respondents 7 or 59 percent are between the ages of 30-39, followed by 4 or 33 percent are in the bracket of 40-49 years old, and the youngest instructor ( 8 percent) is 29 years old. This finding shows that the majority of instructors are middle aged and therefore in the peak of their energies and dynamism. From the perspective of human psychology, teachers at these ages would bring greater benefits to students in particular and the institutions as a whole, as cited by Taguiam (2016).

Regarding their genders, interestingly, all the respondents, 12 or 100 percent are female which supports the belief that teaching is a female-dominated profession.

In terms of English teaching experience, the study shows that half of the respondents ( 6 or 50 percent) have been teaching English for 10-20 years, followed by 4 or 33 percent who are active in the teaching profession from 5 to 9 years and 2 respondents or 17 percent who have been teaching English for more than 20 years. The result indicates that the teacher-respondents were quite experienced, which is supposed to pose a significant advantage to the curriculum/syllabus development at Thai Nguyen University as they can understand learners' psychology and linguistic needs, are aware about teaching strategies and contexts, and at the same time understand the needs of stakeholders. Patankar (2013) stated that success in teaching in the classroom is inextricably linked to curriculum development - everyday decisions on both teaching contents and the most effective way of knowledge transfer. Regarding their experience in syllabus design, 5 respondents or 41 percent claimed that they had less than 5 years of experiences in this professional activity while an equal proportion had 5 to 9 years of experience and only 2 or 18 percent showed strong background from 10 to 20 years of experience. This finding means syllabus design is a newly practiced activity for these instructors and not in accordance with numbers of years in teaching English.

However, with regard to the number of professional training programs attended, only 4 out of 12 teachers claimed that they had ever participated in at least one training program on curriculum development with OBE approach. A striking point is that two third of the respondents reported that they neither remembered nor had a chance to really participate in such an official OBE training on syllabus design at university level. The result is further supported by the claim of Nguyen (2017) that the current English syllabi at 5 different institutions were found to use different formats but the same wording and writing styles (see Table 1).

\subsubsection{Level of Awareness on Outcome-Based Education}

The study investigated the levels of awareness of TNU syllabus designers on OBE in terms of its advantages, major components and constructive alignment. The significant findings regarding these areas are presented in Tables 2-6 that follow. Overall, these educators are aware of the advantages of OBE, its components and alignment with an average mean of 2.83 . This is really a good signal for a successful implementation of this approach in their teaching context.

\subsubsection{Awareness on Advantages of $O B E$}

Table 2 shows the results related to the respondents' level of awareness on OBE in terms of its advantages. At the first glance, it is noticeable that the respondents show full awareness that OBE fosters a better integration between education at school, workplace and higher education levels with a mean of 3.33. The finding poses an advantage for OBE curriculum developers and course designers in order to restructure and redesign the English programs based on OBE, which requires the cooperation of different parties for more fruitful results in education and training.

Generally, the respondents are aware that Outcome-Based Education are really beneficial to their students and teaching practices as reflected in the average mean of 3.13 with the verbal interpretation of aware. These findings are supported by the findings in research conducted by Caguimbal (2013) which revealed that respondents are all 
Table 1. Profile of English syllabus designers

\begin{tabular}{|c|c|c|}
\hline Variables & $\begin{array}{l}\text { Frequency } \\
\qquad(\mathrm{N}=12)\end{array}$ & Percentage \\
\hline \multicolumn{3}{|l|}{ Age } \\
\hline 29 years old & 1 & 8 \\
\hline 30-39 years old & 7 & 59 \\
\hline 40-49 years old & 4 & 33 \\
\hline \multicolumn{3}{|l|}{ Gender } \\
\hline Female & 12 & 100 \\
\hline Male & 0 & 0 \\
\hline \multicolumn{3}{|l|}{ Number of years of teaching English } \\
\hline $5-9$ years & 4 & 33 \\
\hline $10-20$ years & 6 & 50 \\
\hline$>20$ years & 2 & 17 \\
\hline \multicolumn{3}{|c|}{ Number of years of designing English syllabus } \\
\hline$<5$ years & 5 & 41 \\
\hline $5-9$ years & 5 & 41 \\
\hline $10-20$ years & 2 & 18 \\
\hline \multicolumn{3}{|c|}{$\begin{array}{l}\text { Number of training programs on OBE attended (particularly in } \\
\text { curriculum development) }\end{array}$} \\
\hline $0 /$ not remember & 8 & 75 \\
\hline 1 & 4 & 33 \\
\hline
\end{tabular}

aware that OBE approach is really beneficial to students and community. This finding offers a favored condition and potential for the implementation of OBE in the context of Thai Nguyen University (see Table 2).

3.2.4. Awareness of $O B E$ components

Results of the questionnaire as shown in Table 3 indicate that TNU English educators are generally aware of standards of OBE based on three major components namely Intended Learning Outcomes (ILOs), Teaching and Learning Activities (TLAs) and Assessment Tasks (ATs) with an overall mean of 2.69.

In terms of ILOs, it is worth noticing that the respondents are slightly aware of the SMART principle (which stands for Specific, Measurable, Attainable, Relevant, Time-bound) in forming the ILOs with a mean of 1.83 . The vague understanding explains why the syllabi of three (3) out of five (5) school respondents hardly embrace all the characteristics of SMART formula and are rated at the beginning of the process of writing outcomes (Nguyen, 2017).

Table 2. Awareness of Advantages of $O B E$

\begin{tabular}{lccc}
\hline \hline \multicolumn{1}{c}{ Statements } & Mean & SD & Interpretation \\
\hline \hline $\begin{array}{l}\text { 1. OBE promotes the acquisition of the specific skills and competencies in } \\
\text { localities in which there are skill shortages }\end{array}$ & 3.17 & 1.10 & Aware \\
$\begin{array}{l}\text { 2. OBE fosters a better integration between education at school, workplace } \\
\text { and higher education levels }\end{array}$ & 3.33 & 1.06 & Fully aware \\
$\begin{array}{l}\text { 3. OBE helps learners to accept responsibility for learning, as they are now } \\
\text { at the center of the learning process }\end{array}$ & 3.17 & 1.10 & Aware \\
$\begin{array}{l}\text { 4. OBE recognizes prior learning which prevents the duplication and } \\
\text { repetition of previous learning contents } \\
\text { Overall Mean }\end{array}$ & 2.83 & 0.74 & Aware \\
\hline \hline
\end{tabular}

Legend: 3.25 - 4.00 Fully aware; 2.50 - 3.24 Aware; 1.75 - 2.49 Slightly aware; 1.00 - 1.74 Unaware 
In terms of TLAs, English educators at TNU show their strongest understanding about cooperative learning in TLAs that "OBE allows various kinds of groupwork that allow students to collaborate with each other as partners to deal with queries, share concerns or to seek clarification" with a mean of 3.17. Meanwhile, they are close to the level of slight awareness in the statement that "the classroom setting should be on reflective-knowledge mode rather than just knowledge building mode" with a mean of 2.50. This close-to-slight awareness is also confirmed by Nguyen (2017) in the syllabus evaluation result that show a very limited use of functioning knowledge in the syllabi of four school respondents.

Significantly, ATs seem to be the aspect that TNU syllabus developers show their vaguest understanding among other components of ILOs, TLAs, and CA with an average mean of 2.48 and an interpretation of slightly aware. Although TNU English educators know that ATs with well-defined criteria will benefit both assessors and students obviously (2.83) and give students a sense of responsibility and initiative to seek evidences (2.67), they show their weakest awareness in understanding different types of assessment, i.e, direct/ indirect, qualitative/ quantitative, formative/ summative assessment with a mean of 2.17. Moreover, they are also not very aware of the different purposes of assessment, i.e, assessment for learning, of learning and as learning with a mean of 2.25. The slight awareness in ATs is also reflected in the syllabi in which the most frequent activities of assessment are summative tasks with grade and skill focus and there is a lack of formative assessment for students in the majority of school respondents (Nguyen, 2017).

Table 3. Awareness of OBE components

\begin{tabular}{|c|c|c|c|}
\hline OBB components & Mean & SD & Interpretation \\
\hline Intended Learning Outcomes (ILOs) & 2.69 & 0.96 & Aware \\
\hline $\begin{array}{l}\text { 5. OBE begins with the outcomes in mind (ILOs that students exhibit at } \\
\text { the end of learning process) before organizing curriculum, instruction } \\
\text { and assessment }\end{array}$ & 2.83 & 1.06 & Aware \\
\hline $\begin{array}{l}\text { 6. I know exactly what is expected from students before teaching as the } \\
\text { intended outcomes clarify what they need to achieve }\end{array}$ & 3.08 & 1.59 & Aware \\
\hline $\begin{array}{l}\text { 7. I know exactly the intended learning outcomes at the institutional, } \\
\text { program and course levels }\end{array}$ & 3.00 & 0.76 & Aware \\
\hline $\begin{array}{l}\text { 8. I know exactly the SMART formula in determining intended learning } \\
\text { outcomes in OBE }\end{array}$ & 1.83 & 0.40 & Slightly aware \\
\hline Teaching and Learning Activities (TLAs) & 2.90 & 0.86 & Aware \\
\hline $\begin{array}{l}\text { 9. The classroom setting should be on a reflective-knowledge mode } \\
\text { rather than just knowledge building mode }\end{array}$ & 2.50 & 0.90 & Aware \\
\hline $\begin{array}{l}\text { 10. Classroom activities shift in focus from what the teacher does to what } \\
\text { students do }\end{array}$ & 3.08 & 0.93 & Aware \\
\hline $\begin{array}{l}\text { 11. Activities which allow a variety of group work that allow students to } \\
\text { collaborate with each other as partners to deal with queries, share } \\
\text { concerns or to seek clarification }\end{array}$ & 3.17 & 1.02 & Aware \\
\hline $\begin{array}{l}\text { 12. OBE involves varied teaching activities of for "application", } \\
\text { creativity, problem-based learning and lifelong learning }\end{array}$ & 2.83 & 0.57 & Aware \\
\hline Assessment Tasks & 2.48 & 0.77 & Slightly aware \\
\hline $\begin{array}{l}\text { 13. Course preparation assignments are intended to give the students a } \\
\text { sense of responsibility, involvement and initiative }\end{array}$ & 2.67 & 1.13 & Aware \\
\hline $\begin{array}{l}\text { 14. Well-defined assessment criteria makes it clear to both assessors and } \\
\text { learners how assessment will take place }\end{array}$ & 2.83 & 0.88 & Aware \\
\hline $\begin{array}{l}\text { 15. I clearly understand the purposes of assessment, i.e, assessment for } \\
\text { learning, as learning and of learning }\end{array}$ & 2.25 & 0.70 & Slightly aware \\
\hline $\begin{array}{l}\text { 16. I understand deeply about different types of assessment, i.e, direct/ } \\
\text { indirect, qualitative/ quantitative, formative/ summative assessment }\end{array}$ & 2.17 & 0.35 & Slightly aware \\
\hline Overall Mean & 2.69 & 0.86 & Aware \\
\hline
\end{tabular}

Legend: 3.25 - 4.00 Fully aware; 2.50 - 3.24 Aware; 1.75 - 2.49 Slightly aware; 1.00 - 1.74 Unaware 
Table 4. Level of awareness of Constructive Alignment in OBE

\begin{tabular}{lccc}
\hline \multicolumn{1}{c}{ Statements } & Mean & SD & Interpretation \\
\hline $\begin{array}{l}\text { 17. Curriculum mapping is a systematic means of ensuring alignment } \\
\text { among institutional outcomes, graduate attributes, program ILOs and } \\
\text { course ILOs }\end{array}$ & 2.50 & 0.90 & Aware \\
$\begin{array}{l}\text { 18. I know exactly the cycle of planning, learning and assessing in } \\
\text { curriculum design }\end{array}$ & 3.00 & 0.77 & Aware \\
$\begin{array}{l}\text { 19. In syllabus design, I clearly understand that there should be a } \\
\text { combination of four factors: critical knowledge for learners, what we } \\
\text { teach them, how we teach them and how we assess their performance }\end{array}$ & & 0.76 & Aware \\
$\begin{array}{l}\text { 20. The success of learning depends on the alignment among the } \\
\text { intended learning outcomes, all teaching and learning activities and } \\
\text { assessment tasks }\end{array}$ & & 0.74 & Aware \\
\multicolumn{1}{c}{ Mean } & $\mathbf{2 . 8 5}$ & $\mathbf{0 . 7 9}$ & Aware \\
\hline \hline
\end{tabular}

Legend: 3.25 - 4.00 Fully aware; 2.50 - 3.24 Aware; 1.75 - 2.49 Slightly aware; 1.00 - 1.74 Unaware

Table 5. Factors affecting the successful implementation of $O B E$

\begin{tabular}{lccc}
\hline \multicolumn{1}{c}{ Factors affecting the successful implementation of OBE } & Mean & SD & Interpretation \\
\hline \hline 1. Support and pressure from administration & 3.40 & 0.98 & Strongly agree \\
2. Financial support & 3.20 & 0.85 & Agree \\
3. Key staff members and consultants & 3.20 & 0.73 & Agree \\
4. Community support & 3.00 & 0.57 & Agree \\
5. Monitoring and learning from schools that have done it & 3.20 & 0.85 & Agree \\
6. Educational/Professional achievement of teachers & 3.10 & 0.69 & Agree \\
7. Readiness of the students towards Outcome-Based Education & 3.10 & 0.95 & Agree \\
8. Knowledge of teachers about Outcome-Based Education & 3.50 & 1.09 & Strongly agree \\
9. Availability of materials for Outcome-Based Education & 3.30 & 0.84 & Strongly agree \\
10. Time to develop ideas and practice implementation & 3.60 & 1.29 & Strongly agree \\
\multicolumn{1}{c}{ Overall Mean } & $\mathbf{3 . 2 6}$ & $\mathbf{0 . 8 8}$ & Strongly agree \\
\hline \hline
\end{tabular}

Legend: 3.25 - 4.00 Strongly agree; 2.50 - 3.24 Agree; 1.75 - 2.49 Disagree; 1.00 - 1.74 Strongly disagree

\subsubsection{Awareness of Constructive Alignment in $\mathrm{OBE}$}

Table 4 illustrates the level of awareness of Constructive Alignment (CA) in OBE. It is encouraging that overall, English instructors at TNU are aware of the alignment among ILOs, TLAs and ATs in OBE with an average mean of 2.85. However, while the teacher - respondents expressed their level of awareness of the procedure of syllabus design (3.00), the importance of alignment among three standards (2.83), the integration of planning, teaching and assessing (3.08), they all revealed their vague understanding about the alignment among institutional outcomes, graduates attributes, program ILOs and course ILOs with a mean of 2.50 which is at the lowest end of awareness. This finding once again illustrates the incompletion of institutional and program outcomes in all of the five school respondents' syllabi as stated by Nguyen (2017), (see Table 4).

\subsubsection{Factors affecting the implementation of $O B E$}

To investigate the respondents' perceptions on factors that affect the implementation of OBE in TNU, the ten item questionnaires were delivered to the English syllabus designers here.

Results from the data collection show that the respondents strongly agree that support and pressure from administration, teachers' knowledge of OBE, availability of materials and time to implement OBE are major factors that affect the successful implementation of OBE in Vietnam in general and their region in particular. Furthermore, 
the respondents also agree that other factors also involved in promoting good achievement of OBE such as financial support, the present of key staffs and consultants, community support, monitoring from experienced institutions, educational/ professional achievement of teachers and readiness of the students towards OBE play important parts in deciding the success of OBE in their context. With the overall mean of 3.26 and the verbal interpretation of Strongly Agree, it can be concluded that the respondents strongly agree that the success of OBE is subject to many parties including community, institutions, administrators, teachers and students (see Table 5).

\section{DISCUSSION AND CONCLUSION}

Based on the abovementioned findings, the following conclusions were drawn:

English syllabus designers at TNU are experienced in teaching English but lack professional trainings on Outcome-Based Education, particularly in curriculum development in OBE standards.

A good signal for the implementation of OBE at TNU is that TNU educators are aware of the advantages of OBE and know exactly the types of learning and teaching activities taken place in an OBE language classroom. In general, they are aware of the intended learning outcomes and assessment tasks in OBE, though sometimes are not that aware of certain components of designing ILOs and ATs.

Respondents strongly agree that the success of OBE is determined by many factors and active involvement of parties such as community, institution, administrators, teachers and students.

In the light of findings gathered in the study, the researchers hereby recommend that to ensure the successful restructuring of training programs towards OBE standards at TNU in particular and in Vietnam in general, there should be active involvement of different parties such as employers, educational institutions, community, teachers and students, etc, in the area. In addition, appropriate policies should be introduced to encourage full implementation of OBE in curriculum design and classroom teaching. Furthermore, professional training related to Outcome-Based Education should be offered to educators of all levels so that they can thoroughly understand the components of OBE and how to effectively implement it in their particular context.

\section{REFERENCES}

Anh, V. T. P. (2011). Outcome learning. Retrieved from: http://duongdieumd.blogspot.com/ 2011/11/outcomelearning.html

Biggs - Tang (2007). Teaching for quality learning at university (Third edition). The society for research into higher education \& Open University Press, Mc Graw Hill.

Caguimbal, D. et al. (2013). Level of Awareness of the Maritime Students on the Outcomes Based Education. Educational Research International, 2(1), 7-12.

Hoffman, T. G. (1996). An examination of outcome-based education practices, standards, and factors that enhance implementation of $O B E$. PhD. Dissertation, Iowa State University.

Marina Burger (2008). The alignment of teaching, learning and assessment in English home language in grade 10 in District 9, Johannesburg. MA Thesis, University of South Africa.

Mollie Butler (2004). Outcomes based education overview. Unpublished dissertation, University of Sydney, Sydney.

P. S. Patankar, Megha S. J. (2013). Role of Teachers' in Curriculum Development for Teacher Education. For National conference on Challenges in Teacher Education, Physical Education and Sports - Department of Education and Physical Education Mahavir Mahavidyalaya, Kolhapur.

Que, N. T. (2017). Evaluation of General English Program Syllabi towards Outcomes-Based English Curriculum in Vietnam. PhD. Dissertation, Cagayan State University, Philippines.

Spady, W. (1994). Outcomes-Based Education: Critical issues and Answers. Arlington, VA: American Association of School Administrators.

Taguiam, D. (2016). Process Evaluation on the Implementation of Mother Tongue-Based Multilingual Education. Doctoral Dissertation, Cagayan State University, Philippines.

Thai Nguyen University (2013). Project on standardizing language skills for TNU academic staffs and students of the 2013-2015 and the 2016-2020 periods. Retrieved from: http://www.tnu.edu.vn/Pages/-tnuvb-portal_ VanBanPhapQuy-tnudoc-44-tnusite-1.html 